Insight

\title{
From Invisibility to Transparency: Identifying the Implications
}

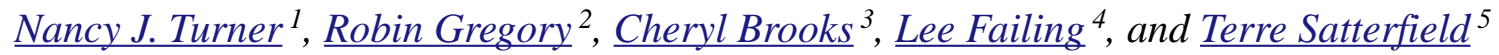

\begin{abstract}
This paper explores the need for a broader and more inclusive approach to decisions about land and resources, one that recognizes the legitimacy of cultural values and traditional knowledge in environmental decision making and policy. Invisible losses are those not widely recognized or accounted for in decisions about resource planning and decision making in resource- and land-use negotiations precisely because they involve considerations that tend to be ignored by managers and scientists or because they are often indirect or cumulative, resulting from a complex, often cumulative series of events, decisions, choices, or policies. First Nations communities in western North America have experienced many such losses that, together, have resulted in a decline in the overall resilience of individuals and communities. We have identified eight types invisible losses that are often overlapping and cumulative: cultural/lifestyle losses, loss of identity, health losses, loss of self-determination and influence, emotional and psychological losses, loss of order in the world, knowledge losses, and indirect economic losses and lost opportunities. To render such invisible losses more transparent, which represents the first step in developing a more positive and equitable basis for decision making and negotiations around land and resources, we recommend six processes: focusing on what matters to the people affected, describing what matters in meaningful ways, making a place for these concerns in decision making, evaluating future losses and gains from a historical baseline, recognizing culturally derived values as relevant, and creating better alternatives for decision making so that invisible losses will be diminished or eliminated in the future.
\end{abstract}

Key Words: First Nations; decision making; resource use; negotiations; cultural values

\section{INTRODUCTION}

Human existence has always depended on our ability to respond and adapt to change. However, rapid change, particularly when enforced from the outside, can have extremely negative consequences. These are compounded when people experience significant losses that are not acknowledged or recognized. If a family is forced from its home, the loss is direct and obvious, and compensation typically is expected. However, if the loss is not obvious to others, is not readily measured, is not represented in a manner recognized as legitimate, or is the result of a series of compounding impacts that are not easily connected to an original action, the consequences can be invisible even though they prove devastating. This unfortunately describes numerous government and industry policies and practices that have affected First Nations' access to traditional lands and resources in western North America.
In this paper we address these profound but "invisible" losses to individuals or communities that are not generally recognized or seen as important by others. In the context of environmental management decisions, they range from indirect impacts not widely recognized, e.g., the loss of a cherished berry-picking site because of urbanization or road construction, to cumulative losses resulting from a complex series of events or decisions, such as a general decline in the productivity of traditional food species because of habitat change from fire suppression over several decades (Deur and Turner 2005) or in the health of wild salmon because of the influences of commercial aquaculture (Krkosek et al. 2006).

The decline or removal of key food sources can introduce a cascading effect in which important associated cultural practices and institutions are also lost, e.g., cessation of "First Salmon" ceremonies following prohibition of associated fishing 
technologies and decreasing salmon populations (Turner and Berkes 2006). As well, such losses may impose changes to an individual's or a community's future options. Invisible losses, by their very nature unrecognized and unacknowledged, are seldom considered, awarded compensation, or mitigated by decision makers and resource managers. Nevertheless, in terms of risk to peoples' overall health and capacity for resilience, such losses may have even more profound impacts on individuals and communities than those that are more visible and widely acknowledged.

We investigate here the nature of invisible losses, focusing on cultural losses experienced by First Nations in western Canada and the United States. However, most of the points made in this paper would apply equally to other Aboriginal communities and to nonindigenous local communities. We discuss why it is important to recognize invisible losses and make them count in decision making, and suggest ways in which they can be made more visible so that the processes and deliberations that tend to obscure them can be altered to render them more transparent.

From a theoretical perspective, we suggest developing and implementing a different way of looking into environmental and social impacts on groups of people. Rather than referring to legal precedents or economics, we are saying: Ask the people who were hurt about the nature of their losses. To make this workable, we also supply the outlines of some analytical tools for integrating a more comprehensive set of losses into evaluations and decision making. We draw on theory from decision analysis, ethnoecology, and behavioral decision making, all of which we cite in the text. Ideas such as constructed preference and the use of performance measures to define losses more precisely are at the forefront of decision sciences theory. In addition, we make a contribution that links decision making, ethnoecology, environment, and social-ecological resilience in the context of cumulative losses.

\section{HISTORICAL CONTEXT}

For North American First Peoples, colonial and industrial history is replete with invisible losses. The invisibility is a function of colonialism itself insofar as one economic and political system was imposed on other very different systems, with little consideration given to the potential impacts. Some losses have since been rendered more visible through the repeated efforts of those who suffered them, or through the efforts of their descendants and advocates. See, for example, the compounding impacts of Canadian residential schools; governments and religious institutions have been forced to acknowledge these effects and provide some compensation for the destruction of the languages, beliefs, and spirituality of indigenous peoples (Indian and Northern Affairs Canada 1996, Fournier and Crey 1997).

Nevertheless, government decision makers still fail to recognize many of the devastating effects of the language suppression, insitutional diet, and general denigration of indigenous cultures and life ways common to residential schools. The erosion of complex traditional knowledge systems, including the loss of opportunity for intergenerational transmission through indigenous language, stories, ceremonies, observation, and participation, is a very real consequence. Seldom identified or acknowledged, this serves as an example of an invisible loss.

Our focus here is on resource management policies that have also had cascading impacts, many invisible and unacknowledged, for indigenous peoples in North America. Examples include the reserve system, which deprived First Peoples of their traditional lands and resources (Government of British Columbia1875); the banning of the Potlatch and associated ceremonies from 1885 to 1952 (Trosper 1998, King 2004); restrictions on landscape burning (Boyd 1999); and an entire series of fisheries and forestry laws that reduced the food security and health of indigenous peoples (Kuhnlein 1992, Turner and Turner 2007). Similarly, policies that destroy traditional economic systems and affect people's security and capacity for resilience have been little addressed in contemporary legal systems (cf. R. vs. Van der Peet 1996 and R. vs. Gladstone 1996; Ommer and Turner 2004).

\section{CHARACTERIZING INVISIBLE LOSSES}

A number of themes emerge when examining the invisible losses incurred by indigenous peoples as a result of land management policies. These are inextricably interconnected, but can be characterized as discrete types of losses worthy of explicit consideration. These losses are often precipitated through dramatic changes in the traditional use of a 
resource, including its extirpation, e.g., the loss of a wild salmon run, prohibition of access, e.g., lands confiscated or ownership transferred to the private sector, or significant changes in quality, e.g., contamination of a traditional food source.

A prime example, at least for indigenous peoples living in western North America, is the dramatic restriction of access to Pacific salmon (Oncorhynchus spp.), a "cultural keystone" species for these peoples (Garibaldi and Turner 2004, Nabhan 2005). The effects of this have been devastating and pervasive. The point is not that the well documented decreases in the number and genetic diversity of salmonid populations have been invisible (King 2004, Krkosek et al. 2006). Rather, despite considerable public attention, little notice has been given to the range and extent of the impacts of losing their salmon on peoples' lives, health, and well-being. Innumerable other resources have been similarly affected, directly and indirectly, by government and industry actions such as the construction of dams, draining of wetlands, clear-cut logging, mining, road building, commercial fisheries, and so forth, but decision makers seldom appreciate or properly account for the full extent of such impacts on First Nations communities.

Eight types of invisible losses are characterized below. These are not intended to be comprehensive; we highlight them as indicators of the broad scope and fundamental nature of the invisible losses experienced primarily by First Nations individuals and communities. In the next section we describe a number of ways in which the identity, magnitude, and severity of these losses can be made more transparent and therefore addressed appropriately in policy and decision making.

\section{Cultural and life-style losses}

When externally imposed forces or decisions negatively impact or prohibit a particular way of life and the cultural values and practices that go with it, the people affected may no longer be able to engage in activities that are fundamental to their culture. As a result, they feel profound loss and alienation. Colonial history is full of episodes in which newcomers sought to change the life ways of local inhabitants or dismissed their practices as inferior or unworthy, resulting in exasperation and despair (Berger 1999, Turner 2005, Berkes 2008, Turner and Turner 2008).

\section{Loss of identity}

Identity is a nebulous yet fundamental construct, widely recognized as basic to human well-being and resilience and a cornerstone of the ability of First Nations to recover from large-scale social and environmental impacts. It tells a people who they are; to whom and where they belong; which practices, e.g., fishing, potlatching, passages or rights, etc., define them; what their individual purpose and role in life is; and how they are distinctive. Cultural expressions of identity can be both material, such as a mask or a landbase, and ideational, e.g., the belief in a trickster spirit or the eternality of names and dances. Furthermore, identity is not a static state; rather, it is like a tapestry to which each additional thread, color, and pattern adds richness and strength. Identity is continually reinforced through key practices and social institutions. The invisible yet pervasive character of identity makes it hard to pin down the precise nature of what is lost. Nevertheless, the impacts of lost identity are devastating and highly correlated with such evils as teenage suicide, alcoholism and addiction, and violence (Kirmayer et al. 2000).

\section{Health losses}

Whereas obvious pollution and measurable industrial impacts on food resources may be recognized and compensated for, the effects of pollutants on food sources are often more subtle and, in a sense, more insidious. Even small amounts of pollutants can affect food taste and quality (Kuhnlein et al. 1982), leading to health and safety concerns and ultimately to the elimination of foods such as clams or seagull eggs from the traditional diet. Once this happens, the knowledge related to harvesting and preparing these foods diminishes. Then, even if the quality of the food improves, its consumption may not be resumed (Kuhnlein 1992). Eventually, the entire diet transforms away from local, traditional food toward processed, marketed food of lower quality, which increases the risk of health effects like heart disease and diabetes (Wong 2003). Moreover, because locally produced food is often part of a larger subsistence economy, its loss can greatly intensify poverty by forcing people into greater reliance on external market-based products. Such indirect and cumulative risks are seldom linked to environmental pollution. 


\section{Loss of self-determination and influence}

One of the worst possible punishments is to take away people's ability to control their own lives. Nevertheless, enforced loss of self-determination has been a common, ongoing story for First Peoples. The entire Indian reserve system represents such a loss. Individual testimony during the McKennaMcBride Royal Commission hearings of 19121914 in British Columbia reflects the distress that those testifying felt from losing so much of their lands and livelihoods because of imposed government policy. A plethora of government restrictions and regulations continues to this day, in areas such as water use, tree cutting, fishing, hunting, and gathering plant foods, materials, and medicines, that prevents people from reassuming control over their resources. This includes curtailment of peoples' ability to manage and enhance their resources, thus causing further depletion of their traditional foods and other cultural products. For example, restrictions on the landscape burning practices of indigenous peoples have reduced productivity and biological diversity across various ecosystems, causing overall resource depletion, and made forests more susceptible to insect infestations and catastrophic wildfire (Boyd 1999, Pyne 2002). Establishing parks and protected areas on First Nations territories has further impeded traditional management and access (Deur and Turner 2005, Sinclair and Ommer 2006).

\section{Emotional and psychological losses}

The ability to provide for one's family and fulfill obligations to one's culture is central to a person's self-confidence, self-esteem, and feelings of worthiness. When this ability is denied, it can lead to frustration, helplessness, and loss of self-respect that can last an entire lifetime and affect a whole family or community. Many situations, seldom recognized or acknowledged, can cause this type of loss. One example is the shame and sadness that for many First Nations has accompanied their forced relocation, e.g., because of mining or dam construction, away from their ancestral lands to another place in which some traditional practices may no longer be possible because of lack of access to sacred sites or familiar resources (Tsay Keh Dene Band et al. 2006). Access denied to traditional fishing grounds, camping spots, harvesting areas, or sacred sites also means an inability to pass on the knowledge associated with these sites to younger generations.

\section{Loss of order in the world}

Apprehension and confusion can result from external changes that affect the expected and anticipated cycles of life, including disruptions of the regular return of migratory species or changes in the seasons. Stemming from development, enforced relocation, restricted access to former territories, or climate change, these factors affect peoples' security and well-being at a fundamental level, often resulting in profound disorientation. Feelings of helplessness and anxiety may affect peoples' entire lives and livelihoods, yet not be acknowledged or recognized by others, including those who caused the disruption. The Inuit peoples of Alaska and northern Canada, who for generations have marked the coming of the seasons with activities and ceremonies related to the migrations and cycles of both aquatic and terrestrial animals, provide a good example (Manseau et al. 2005). In recent decades, the timing of these ceremonies has changed: Activities that used to take place in early June may now occur in early May or even late April because of global warming and associated temperature and precipitation changes (Krupnik and Jolly 2002). Such changes also affect the social relations within a community. Individuals or families who are known for their relationship to a natural resource, e.g., the best fishers, trackers, and clam diggers and makers of harpoons, spears, and nets, can, over time, lose the respect and honor associated with their skills if the resource disappears or is adversely affected.

\section{Knowledge losses}

The traditional ecological knowledge of indigenous peoples is generally transmitted orally and through cultural processes that include observation, demonstration, participation, and stories, ceremonies, and teachings at particular times of one's life or during special occasions such as feasts and potlatches (Turner et al. 2000). Many regulations imposed by colonialism and government policy, such as residential schools and the banning of the potlatch and certain fishing practices, to name just a few, have curtailed or outright prohibited these forms of knowledge transmission from generation to generation (King 2004). Other factors, such as the necessary participation of many indigenous people in the wage economy when their traditional livelihoods were no longer available, have also resulted in barriers to intergenerational knowledge transmission. Collectively, the cascading effects 
have eroded traditional knowledge, including indigenous languages, to the point at which many young indigenous people do not know how to identify some of the most common traditional foods of their grandparents' generation or how to survive in places in which their ancestors have lived for hundreds of years. This knowledge is not simply for the benefit of the individual; the traditional land and resource management practices that represent a practical manifestation of this knowledge help to maintain and enhance habitats and resources, and, without the application of this traditional knowledge, these resources have noticeably declined (Berkes 2008). This overwhelming, but as yet little recognized, erosion of cultural diversity parallels, and is linked to, the escalating loss of global biodiversity (Davis 2001, Carlson and Maffi 2004).

Many traditional activities are seasonal and place based. Traditional education, including instilling children with traditional values, is curtailed or eliminated altogether if children miss out on seasonal activities that take place during the school year. If families take their children out of school, they worry that the children will fall behind in their schoolwork and will not be able to catch up, putting them at a disadvantage in mainstream society. However, if they do not take their children out, for example, to harvest herring eggs or pick seaweed, the children won't be able to learn the harvesting skills, the preserving skills, the safety skills, and all the place-based knowledge of the lands and waters of their home territories that is the basis of their culture and, ultimately, their security. They will also miss the chance to gain other important knowledge such as family history and stories, the things that only extended and intimate time together in a family group will allow.

\section{Indirect economic losses and lost opportunities}

If the range of cultural losses and impacts on peoples' health and well-being are little recognized by those whose actions cause these losses, the loss of opportunities for a community's own economic development is almost never acknowledged. In most situations, the financial benefit for those implementing an action, such as building a dam for hydro development, constructing a road or railroad, logging a forest, or developing a ski resort, means a lost opportunity for local peoples to use those areas and resources in different, and often more sustainable, ways. For example, in the discussions around increasing tanker traffic on the north coast of British Columbia if pipelines are built to Kitimaat from the Alberta oil patch, the plans of the coastal communities for developing ecotourism opportunities or sustainable shellfish culture ventures are generally not factored into the equation of the major players. This is one form of what economists call "opportunity costs," the loss of future benefits as a result of taking actions that preclude some types of future options. Similarly, the impacts of such traffic on fish, whales, and other marine life that are so closely connected culturally and spiritually with the lives and well-being of coastal First Nations are rarely considered.

Another type of lost opportunity, difficult to frame but nonetheless real, can be called the loss of the ability to focus forward. Cheryl Brooks (personal communication) frames this as follows: "So much of our [indigenous peoples'] leadership time and energy is dedicated to resolving these past injustices and concerns, for example, locating and repatriating stolen artifacts, changing policies that allow for the apprehension and removal of our children from Aboriginal communities, resolution of the land claims questions; so many of our energies are focused on trying to fix the injustices of the past that it is hard to focus on moving forward and seizing opportunities that might otherwise be available. In many cases we are so involved with trying to serve and or fix broken individuals and spending enormous sums of money on this, that we can't pursue opportunities."

The eight themes described above overlap with each other; most are exacerbated by the compounding of two or more effects in a turmoil of interlinked causes and effects that are exceedingly difficult to distinguish (Turner and Turner 2008). In many cases, the combination of these different kinds of losses adds up to a loss of resilience, or "backup" systems, for First Nations communities. The loss of self-identity, the erosion of economic opportunities, and the absence of an intact social structure to transmit knowledge across generations all result in a lowered ability to withstand change and to respond with confidence and in positive ways that sustain and reinforce traditional cultures. As such, these losses accumulate and profoundly affect not only individuals but entire communities and multiple generations. As a result, an added threat from a new development, such as a ski resort or an aquaculture facility, can be devastating. 
One example of this complexity and loss of resilience is in northern Alberta, where numerous Métis settlements have been adversely affected by industrial development, particularly in the oil and gas sector. Key activities, including subsistence hunting, fishing, and gathering, have been given little standing as part of current compensation agreements, and there is scant recognition of their important role in the ongoing cultural, social, and spiritual life of the community. Of particular concern to the Métis are a variety of activities and associated ceremonies that used to occur on a regular basis in response to natural events, such as the return of certain species and the breakup of ice in the lakes, but now no longer take place because of decreases in the available number of animals, restrictions placed on people's movements, or the contamination of food sources, e.g., by leakage from oil and gas wells. These losses are rarely included in compensation agreements; most involve nonmarket resources for which conventional economic markets do not exist (McDaniels and Trousdale 2005, TEK Project 2006).

\section{DISCUSSION: TOWARD MAKING INVISIBLE LOSSES TRANSPARENT}

Given the complex and broad-ranging nature of the invisible losses described above, what can decision makers do to better characterize these losses, make them more visible, and include them in meaningful ways as part of consultations, negotiations, and policy formulation? Clearly, the challenges these questions present are immense, and we cannot hope to address everything. We focus here on six key questions that we believe can and must be addressed in decision processes to help expose, describe, and account for invisible losses:

1. How do policy and decision makers identify what matters most to the people affected, even when this is hard to articulate and even harder to quantify?

2. How can invisible losses, including cultural losses, be described and acknowledged in ways that are meaningful and compelling to other stakeholders, decision makers, and regulators?

3. How can invisible concerns be made transparent and, in turn, given a central place in decisions that affect the lives of First Nations members?
4. What are concrete ways to acknowledge past conditions of invisible losses so that future losses and gains are put in perspective and can be evaluated more accurately?

5. How can culturally derived values forming an important part of knowledge be acknowledged and accommodated in decision making?

6. How can better management alternatives be created that are both responsive to past invisible losses and able to begin to repair some of the past damage, in part by not continuing to create/perpetuate new damage and invisible losses into the future?

These questions lead to corresponding processes or actions, which are considered in the following discussion. The eight types of invisible losses and the six processes suggested to help reduce invisible losses are represented schematically in Fig. 1.

\section{Focusing on what matters}

Rapid, profound changes in ecological conditions because of hydroelectric dam construction or climate change and the associated disruption of social systems, village relocations, and changes in traditional life-styles and the roles of individuals and governance have led to major breaks in the transmission of spatially specific knowledge and are causing a breakdown in entire knowledge and social systems (Kirsch 2001). In spite of that, decisionmaking processes involving First Nations communities often focus only on what politicians, lawyers, or scientists have identified as important. Discussion is directed to factors that are politically prominent, professionally interesting, readily identifiable, or easily quantifiable, but may overlook the perspectives of those who are the most affected. For example, the courts still tend to give less credibility to oral history or the oral testimony of elders than to written "academic" or "expert" information.

An alternative view, one that has gained prominence since the publication of the influential report Understanding Risk (U.S. National Research Council 1996), is to focus on those things that matter to the people living in an impacted community. Techniques for, e.g., eliciting values in a defensible 
Fig. 1. Schematic diagram showing eight identified types of invisible losses, to be addressed or counteracted by six processes that may help alleviate these types of losses.

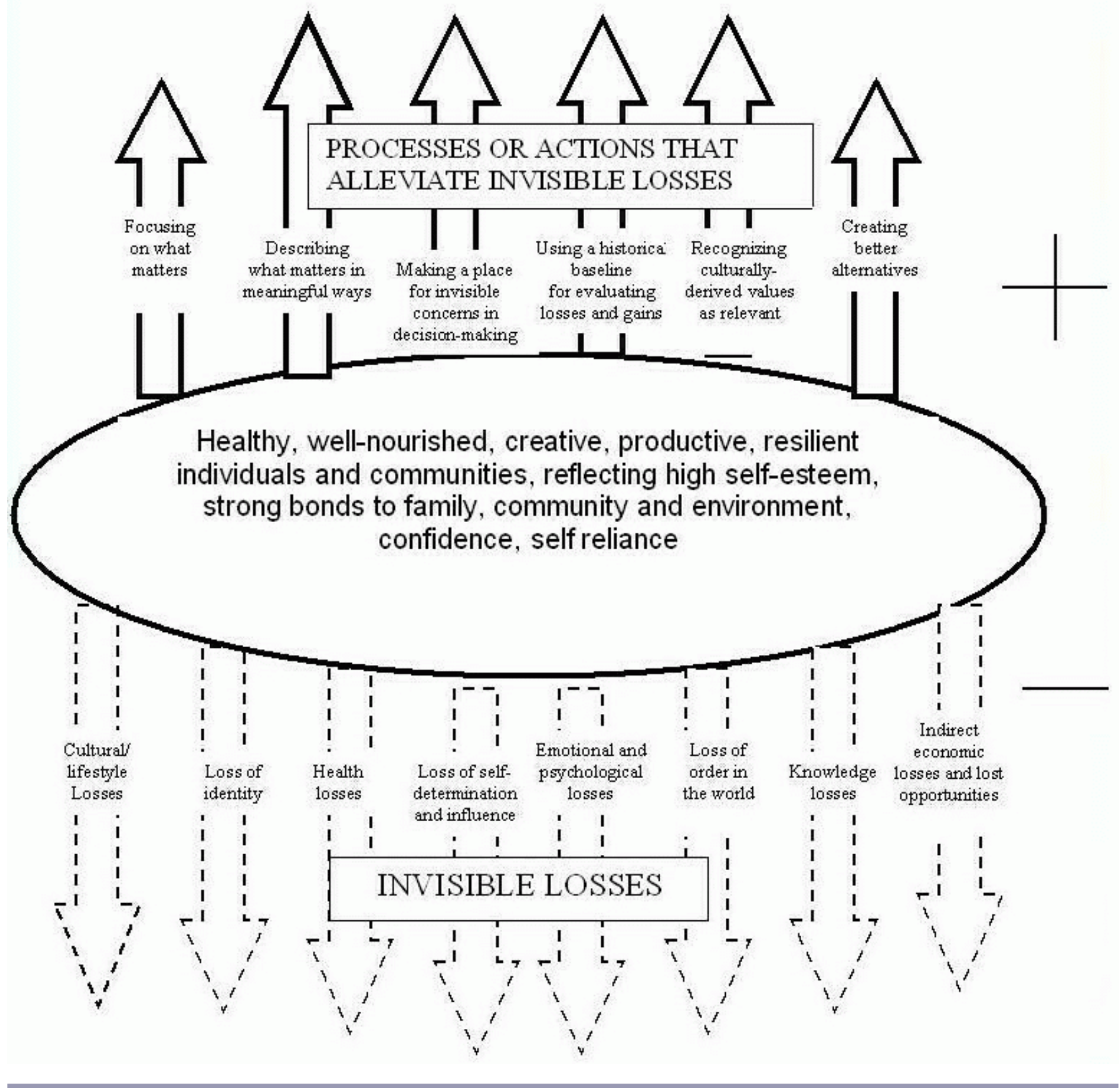


manner or presenting this information in a way that facilitates better decision making have been advanced by decision analysts, psychologists, anthropologists, and others with an interest in making environmental compensation agreements and choices more democratic. A key concept is that of "value-focused thinking" (Keeney 1992), an approach for exposing and clarifying what matters to those affected in their own language and in a way that reflects their own terms and concepts. Such approaches can provide a crucial starting point for consultations that help to make visible a wide variety of environmental, social, and cultural priorities (Gregory et al. 2007).

\section{Describing what matters in meaningful ways}

Of critical importance to many First Nations is not simply what the losses are but also how they are represented and described. To represent loss is, in part, to represent lived experience, which can be anything from grief over the disappearance of a language to narratives of activities no longer possible. Increasingly, it is recognized that oral and life-history narratives, including audiovisual representations, are acceptable ways of articulating both knowledge and experience. These include narratives as conveyed through public venues or personal interviews of cosmological origin and attachment to a homeland, or those explaining the physical or historical impacts of colonialism and other external forces (Basso 1997, Cruikshank 2005).

Simply providing opportunities for individuals to express, in their own words, their frustrations or feelings can enable others to understand a situation more fully. Courts of law, by allowing victim impact statements in serious crime cases, give formal recognition to the right of individuals to give voice to their own reactions in the case of an injustice or trauma. An example of a meaningful and effective personal impact description comes from an Anishenaabe fisherman, testifying about mercury poisoning (Shkilnyk 1985:192): "Everyday I used to bring home fish. One day I got a letter from the government saying that I had a high mercury level. I think it was over 200. The letter said I was at risk. But what does that mean? ... I sometimes get angry at this here mercury ... but I don't know what to do about it."

The Supreme Court of Canada (Delgamuukw vs. British Columbia 1997) confirmed that oral history is legitimate legal evidence, to be treated as equal in weight to written or documentary evidence. Today, many community mapping, videography, and related visual representations of traditional knowledge, place names, and cultural traditions are widely used for purposes of community education, government-to-government deliberations, and group decision making for individual First Nations communities or co-management purposes.

Sometimes a comparison or metaphor that may have meaning to others from a different culture may be an effective means to convey cultural loss; for example, describing a sacred cave or prayer pool as "a cathedral" may help those without experience in indigenous sacred geography to better understand a value. Framing a traditional harvesting area as a grocery store can convey its importance in terms of providing food security. Terms like "cultural keystone species" may help ecologists and other scientists to understand the crucial role of species such as western red-cedar and salmon to the cultures and cultural identity of indigenous peoples (Garibaldi and Turner 2004).

Using more quantitative assessments may also assist in recognizing and evaluating invisible losses alongside other categories of costs and benefits (Gregory 2000). Even simple numeric scores, such as a 1-5 index to denote different levels of impact on a site of significance such as a burial ground, can help to render visible a previously ignored impact. One example of the use of such a constructed scale comes from work done with the Yakima First Nation in eastern Washington State in the context of the proposed siting of a hazardous waste treatment facility. Rather than trying to measure the "value" of nearby sacred sites, which would be rejected by the participants, a simple scale was developed to compare the distance of proposed facilities from sacred sites; preferred facilities were located farther away. This made it possible to factor into the equation the impact of the facility on sacred sites, and any facilities that might seriously affect a sacred site could be eliminated from further consideration without assigning an explicit value to the sites themselves (Keeney and Gregory 2005).

\section{Making a place for invisible concerns in decision making}

Although the use of narratives, metaphors, cultural practices, or place names may help First Nations express what matters to them meaningfully, other 
audiences such as planners, policy makers, and stakeholders may be indifferent to such messages or uncertain how to deal with them in a decisionmaking context. Typically, they must find ways to express and compare losses or gains across categories of impact and across various management or policy alternatives under consideration. Although absolute measures of loss may not be appropriate, often it is possible to demonstrate relative desirability by comparing the presumed benefits of a proposed action, e.g., new jobs, against its costs, e.g., possible contamination of a food source, or the benefits or losses associated with one proposed action against those of an alternative. Usually, multiple kinds of impacts are considered; decision makers need help in placing invisible losses in perspective with other compelling issues. A useful framework for doing this is multiattribute evaluation (Keeney and Raiffa 1993). In contrast to cost-benefit analysis, multi-attribute analysis reports impacts in natural units and focuses decision makers on the nature of the impact and the trade-offs with other kinds of impacts. Failing et al. (2007) have documented success in using decision analysis tools in a multi-attribute framework to evaluate impacts of importance to First Nations communities, including impacts related to cultural and spiritual values.

An example comes from a multistakeholder wateruse planning process at the Campbell River hydroelectric facility on Vancouver Island. The focus was to evaluate alternative flow regimes downstream from a dam, with the goal of balancing power generation, recreation interests, and fish impacts. Beginning with a value-focused thinking approach, participants were encouraged to articulate what mattered to them in terms of water flows and why. It became apparent that the current configuration of the dam facility violated a fundamental principle of the We Wai kum (Campbell River) First Nation, which is that water flowing naturally in one direction, in this case west, should not be made to flow in the opposite direction. An attribute was created to report which alternatives under consideration violated this principle, and, in consideration with attributes for power production, salmon habitat, and recreational quality, new alternatives were developed to avoid violating it. This was clearly a crude placeholder for a much richer dialogue, but it served the purpose of making the concern transparent and putting the loss created by a violation of principle on an equal footing, i.e., in the same matrix of consequences, with more conventional expressions of impact.

\section{Recognizing a historical baseline for evaluating losses and gains}

One reason why losses can remain invisible is because of our usual choice of baseline for making assessments. In most resource management decision-making contexts, a base case is established representing current conditions. Aboriginal people often argue that this is either incorrect or insufficient. For them, the real benchmark is the historical condition, and current conditions already represent significant losses compared with the past. Many communities have witnessed generations of losses. Thus, when decision makers base their analyses on the status quo, this represents a profound injustice, another form of invisible loss. In fact, our perceptions do shift according to our experience, so that the concept of a "big tree" or a "big halibut" has a different meaning for the residents of coastal British Columbia in the 21 st century than it did to the generations who lived there in the 19th or early 20th centuries (Pauly et al. 2000).

Many decision makers, on the other hand, pragmatically state that, because processes cannot go back in time, the only relevant baseline is the current condition, with changes reported as losses or gains from there. Nevertheless, a large body of economic theory and applied research clearly demonstrates that people consistently and significantly value losses more than foregone gains of an equivalent magnitude (Kahneman and Tversky 1979). Thus, the choice of reference point and the way in which the impact is framed do matter.

\section{Recognizing culturally derived values as a relevant input}

One category of invisible loss, described earlier, is the loss of influence or self-determination. For Aboriginal communities, this typically means a loss in the ability to influence decisions about the resources on which they depend and which, based on assertions of Aboriginal title, they rightfully own. This is closely linked to a loss of respect for culturally derived values and wisdom in resource management. Researchers often hear claims that a decision-making process did not adequately deal with traditional knowledge, whereas managers and academics, having diligently conducted interviews and collected facts from elders, contend that they are "incorporating" traditional knowledge. The problem is that the definition of knowledge by the scientific community is at variance with knowledge 
as understood by Aboriginal knowledge holders. Academics try very hard to provide objective, factbased inputs involving knowledge about "what is, \&\#8221 e.g., where fish spawn, how they are affected by different water flows, etc., excluding, or at least attempting to exclude, subjective value judgments about "what should be." Many Aboriginal participants, on the other hand, explicitly include both fact-based judgments, e.g., where fish spawn, and value-based judgments, e.g., spawning habitat should not be altered. Often, decisionmaking processes will conclude that there is no traditional knowledge on, say, the subject of mining or climate change because there is no historical factbased knowledge about these processes. Nevertheless, there often are relevant, culturally based value judgments to be considered in such cases (Nadasdy 1999). Recognizing that values are part of knowledge means that there must be space for valuebased discussions in any decision-making process whose intention is to restore the voice of Aboriginal communities in the management of resources (Turner et al. 2000, Failing et al. 2007).

\section{Creating better alternatives}

Only over the past few years have policy makers begun to sit down with the parties who have been affected by changes to the environment and elicit their input into developing new management and compensation alternatives. A significant body of theoretical and practical work shows that improved alternatives often can be created if careful attention is given to ways in which those things that matter most to people can be profiled (Keeney 1992). Building on language introduced earlier, the best way to create broadly responsive alternatives is to engage in participatory, value-focused thinking that accounts for historical conditions and brings attention to losses, as well as gains, that might otherwise be rendered invisible.

One of the advantages of value-responsive alternatives is that ways can be found to satisfy what might first appear to be hopelessly contradictory values. In work in Malaysia, for example, a landuse planning process was initially framed as a choice between a development option, specifically the mining of thermal coal reserves, and the preservation option of protecting biodiversity within the pristine rainforest (Gregory and Keeney 1994). Scientific analyses fell into two camps, one favoring economic development and the other environmental preservation. Further analysis was poised to focus on improving the quality of the associated baseline data by reducing the uncertainties that distinguished these two options. Instead, value-focused thinking transferred the attention of decision makers from these alternatives back to the underlying objectives, resulting in alternatives that all parties agreed could provide both ecological protection and economic benefits. Scientific studies were then reassigned to a new set of issues and questions. In this decision-making situation, as in many others, reaching agreement and making a good decision hinged not on resolving differences in scientific opinion, but on creating new and better alternatives based on an exploration of stakeholder objectives.

Given the nature of the indirect, cumulative, and interconnected invisible losses identified here, it seems unlikely that they can be addressed by simple tweaks of the status quo. What is needed is a commitment to explore new and innovative alternatives. Various co-management schemes that directly involve First Nations, and often other local, residents in the resolution of natural resource conflicts recognize a fundamental redistribution of power and, as such, provide a good forum for the development of innovative alternatives (Berkes 2008). It takes time and resources to identify, implement, and evaluate such novel processes and alternatives. These activities also require a multidimensional framework that allows fundamentally different kinds of costs and benefits to be given equal visibility and standing in the process.

\section{CONCLUSION}

This paper has explored a range of issues related to the need for a broader and more inclusive approach that recognizes the legitimacy of cultural values and traditional knowledge in environmental decision making. We have used the term "invisible losses" to describe indirect and cumulative losses that have not been adequately acknowledged, recognized, or addressed in the past. We stressed the need to recognize and accommodate invisible losses, past and present, alongside the more easily measured, observed, and understood impacts of development and discussed some aspects of recognizing and characterizing invisible losses.

We hope that these ideas will help to alert planners, policy makers, and negotiators to the critical 
importance of recognizing and incorporating the full spectrum of impacts incurred by local communities from resource development and to the fact that there are practical methods for making these impacts more visible and relevant in decision making and policy. This is only possible through an inclusive consultation process that allows individuals to express themselves fully in their own words, facilitates the comprehension of decision makers through culturally appropriate and mutually understandable means, and creates a place for the consideration of cultural perspectives and values in ways that are decision relevant, using measures that successfully bring into the equation attributes that were previously felt to be "intangible" or "invisible."

Deciding how to accomplish this requires recognition of the consultation context: the nature of the environmental management problem, the extent of prior losses, the role of different stakeholders and tribal participants, and the forum selected for discussions, e.g., informal meetings vs. structured deliberations or court proceedings. Drawing from our analysis, we suggest six practical steps or processes that can increase the visibility and influence of these impacts in decisions and policies:

1. Focus on what matters to the affected people.

2. Describe the important issues in meaningful ways, using narratives, stories, and visuals.

3. Make a place for these issues and concerns in decision making, using a multidimensional framework and incorporating hard-toquantify impacts.

4. Acknowledge historical losses by evaluating activities from a historical baseline rather than just from the present.

5. Recognize culturally derived values as relevant and significant, and include them as legitimate inputs to decisions.

6. Create better alternatives to decision making, so that invisible losses will be diminished or eliminated in the future.

Undertaking these initiatives may require more time to develop necessary relationships and to enable people's concerns to be heard and considered. In the end, however, the extra time and effort will pay off in the form of more effective and satisfactory environmental management decisions and in the improved health and well-being of both Aboriginal communities and the larger society.

There will always be losses to individuals and communities caused by the actions of others, but with care and attention these losses can be minimized, and decision makers can demonstrate their sincerity and intent and find lasting solutions through listening followed by action, by the mitigation of adverse impacts, and through fair compensation or accommodation. A major need is for comprehensive, meaningful dialogue and involvement that covers the things that matter to local communities, including valuing culture and traditional knowledge and finding ways for these to truly influence environmental decisions and resource-based negotiations. Ultimately, a goal of all good community-based decision making is to allow people to voice and represent their concerns, to convey what matters, and to express their views in a manner that renders them understandable to decision makers (Battiste and Henderson 2000). Acknowledging, respecting, and addressing the historical, current, and potential future invisible losses of First Nations communities is essential to sustainability for all of us.

Responses to this article can be read online at: http://www.ecologyandsociety.org/voll3/iss2/art7/responses/

\section{Acknowledgments:}

Conversations with many people have contributed to the ideas in this paper, including Earl Claxton Sr., Helen Clifton, John Elliott Sr., Lynne Hill and Ernie Hill Jr., Dr. Mary Thomas, Chief Adam Dick, Greg Sam, Dr. Daisy Sewid-Smith, Kim RecalmaClutesi, Graham Long, and William Trousdale. A special thanks to Janis Brooks, who helped with the inception of this paper. We are also grateful to the editors and to two anonymous reviewers of an earlier draft of this paper for their constructive and helpful suggestions. Funding has been provided through Award SES-0451259 to Decision Research from the U.S. National Science Foundation, Program in Decision, Risk, and Management Science, and from Social Sciences and Research Council of Canada awards (\#17R27953 to Terre Satterfield and \#410-2005-1741 to Nancy Turner). 
The ideas expressed in this paper are those of the authors alone.

\section{LITERATURE CITED}

Basso, K. 1997. Wisdom sits in places: landscape and language among the western Apache. University of New Mexico Press, Albuquerque, New Mexico, USA.

Battiste, M., and J. S. Youngblood Henderson. 2000. Protecting indigenous knowledge and heritage. Purich Publishing, Saskatoon, Saskatchewan, Canada.

Berger, T. R. 1999. Long and terrible shadow: white values, native rights in the Americas, 1492-1992. Douglas and McIntyre, Vancouver, British Columbia, USA.

Berkes, F. 2008. Sacred ecology: traditonal ecological knowledge and resource management. Second edition. Taylor and Francis, Philadelphia, Pennsylvania, USA.

Boyd, R., editor. 1999. Indians, fire and the land in the Pacific Northwest. Oregon State University Press, Corvallis, Oregon, USA.

Carlson, T. J. S., and L. Maffi, editors. 2004. Ethnobotany and conservation of biocultural diversity. Advances in Economic Botany, Volume 15. New York Botanical Garden Press, Bronx, New York, USA.

Cruikshank, J. 2005. Do glaciers listen? Local knowledge, colonial encounters, and social imagination. University of British Columbia Press, Vancouver, British Columbia, Canada, and University of Washington Press, Seattle, Washington, USA.

Davis, W. 2001. Light at the edge of the world: a journey through the realm of vanishing cultures. Douglas and McIntyre, Vancouver, British Columbia, Canada, and National Geographic Society, Washington, D.C., USA.

Deur, D., and N. J. Turner, editors. 2005. "Keeping it living": traditions of plant use and cultivation on the northwest coast of North America.
University of Washington Press, Seattle, Washington, USA, and University of British Columbia Press, Vancouver, British Columbia, Canada.

Failing, L., R. Gregory, and M. Harstone. 2007. Integrating science and local knowledge in environmental decisions: a decision-focused approach. Ecological Economics 64(1):47-60.

Fournier, S., and E. Crey. 1997. Stolen from our embrace. Douglas and McIntyre, Vancouver, British Columbia, Canada.

Garibaldi, A., and N. Turner. 2004. Cultural keystone species: implications for ecological conservation and restoration. Ecology and Society 9(3): 1. [online] URL: http://www.ecologyandsociety. org/vol9/iss3/art1.

Government of British Columbia. 1875. Papers connected with the Indian Land Question, 18501875. (Reprinted 1987 as Indian Land Question, 1850-1875, 1877.) Government Printer, Victoria, British Columbia, Canada.

Gregory, R. 2000. Using stakeholder values to make smarter environmental decisions. Environment 42:34-44.

Gregory, R., L. Failing, and M. Harstone. 2007. Meaningful resource consultations with First Peoples: notes from British Columbia. Environment 50(1):34-45.

Gregory, R., and R. Keeney. 1994. Creating policy alternatives using stakeholder values. Management Science 40:1035-1048.

Indian and Northern Affairs Canada. 1996. Report of the Royal Commission on Aboriginal Peoples. Available online at: http://www.ainc-inac. gc.ca/ch/rcap/sg/sgmm e.html.

Kahneman, D., and A. Tversky. 1979. Prospect theory: an analysis of decision under risk. Econometrica 47:263-291.

Keeney, R. 1992. Value focused thinking: a path to creative decision making. Harvard University Press, Cambridge, Massachusetts, USA.

Keeney, R., and R. Gregory. 2005. Selecting attributes to measure the achievement of objectives. Operations Research 53:1-11. 
Keeney, R., and H. Raiffa. 1993. Decisions with multiple objectives. Cambridge University Press, New York, New York, USA.

King, L. 2004. Competing knowledge systems in the management of fish and forests in the Pacific Northwest. International Environmental Agreements: Politics, Law and Economics 4:161-177.

Kirmayer, L. J., G. M. Brass, and C. L. Tait. 2000. The mental health of Aboriginal peoples: transformations of identity and community. Canadian Journal of Psychiatry 45(7):607-616.

Kirsch, S. 2001. Lost worlds: environmental disaster, "culture loss," and the law. Current Anthropology 42(2):167-198.

Krkosek, M., M. A. Lewis, A. Morton, L. N. Frazer, and J. P. Volpe. 2006. Epizootics of wild fish induced by farm fish. Proceeds of the National Academy of Science (USA) 103:15506-15510.

Krupnik, I., and D. Jolly. 2002. The Earth is faster now: indigenous observations of Arctic environmental change. Arctic Research Consortium of the United States, Fairbanks, Alaska, USA, and The Smithsonian Institution, Washington, D.C., USA.

Kuhnlein, H. V. 1992. Change in the use of traditional foods by the Nuxalk native people of British Columbia. Ecology of Food and Nutrition 27:259-282.

Kuhnlein, H. V., A. C. Chan, J. N. Thompson, and S. Nakai. 1982. Ooligan grease: a nutritious fat used by native people of coastal British Columbia. Journal of Ethnobiology 2(2):154-161.

McDaniels, T., and W. Trousdale. 2005. Resource compensation and negotiation support in an Aboriginal context: using community-based multiattribute analysis to evaluate non-market losses. Ecological Economics 55:173-186.

Manseau, M., B. Parlee, and G. B. Ayles. 2005. A place for traditional ecological knowledge in resource management. Pages 141-164 in F. Berkes, R. Huebert, H. Fast, M. Manseau, and A. Diduck, editors. Breaking ice: renewable resource and ocean management in the Canadian north. University of Calgary Press, Calgary, Alberta, Canada.
Nabhan, G. P. 2005. Renewing Salmon Nation's food traditions. Ecotrust, Portland, Oregon, USA.

Nadasdy, P. 1999. The politics of TEK: power and the 'integration' of knowledge. Arctic Anthropology 36(1/2):1-18.

Ommer, R. E., and N. J. Turner. 2004. Informal rural economies in history. Labour/Le Travail: Journal of Canadian Labour Studies 53:127-157.

Pauly, D., V. Christensen, R. Froese, and M. L. D. Palomares. 2000. Fishing down aquatic food webs. American Scientist 88:46-51.

Pyne, S. J. 2002. Fire: a brief history. University of Washington Press, Seattle, Washington, USA.

Shkilnyk, A. M. 1985. A poison stronger than love: the destruction of an Ojibwa community. Yale University Press, New Haven, Connecticut, USA.

Sinclair, P. R., and R. E. Ommer, editors. 2006. Power and restructuring: Canada's coastal society and environment. ISER Books, Memorial University of Newfoundland, St. John's, Newfoundland, Canada.

TEK Project. 2006. Integrating traditional environmental knowledge in land reclamation. Fort McKay_Albian Sands Energy Inc. TEK Project, Fort McKay, Alberta, Canada.

Trosper, R. L. 1998. Incentive systems that support sustainability: a First Nations example. Conservation Ecology 2(2): 11. [online] URL: http://www.consec ol.org/vol2/iss2/art11/.

Tsay Keh Dene Band, Kwadacha Nation, Office of the Premier, and BC Hydro. 2006. News release: agreement settles decades of flooding impacts, Dec. 12, 2006. Available online at: http:// www2.news.gov.bc.ca/news releases 2005-2009/2 0060TP0184-001498.pdf.

Turner, N. J. 2005. The Earth's blanket: traditional teachings for sustainable living. Douglas and McIntyre, Vancouver, British Columbia, Canada, and University of Washington Press, Seattle, Washington, D.C. USA.

Turner, N. J., and F. Berkes. 2006. Coming to understanding: developing conservation through 
incremental learning. Human Ecology (Special Issue on Developing Resource Management and Conservation) 34(4):495-513.

Turner, N. J., M. B. Ignace, and R. Ignace. 2000. Traditional ecological knowledge and wisdom of Aboriginal peoples in British Columbia. Ecological Applications 10(5):1275-1287.

Turner, N. J., and K. L. Turner. 2007. "Rich in food": traditional food systems, erosion and renewal in northwestern North America. Indian Journal of Traditional Knowledge 6(1):57-68.

Turner, N. J., and K. L. Turner. 2008. "Where our women used to get the food": cumulative effects and loss of ethnobotanical knowledge and practice; case studies from coastal British Columbia. Botany 86(1):103-115.

U.S. National Research Council. 1996. Understanding risk: informing decisions in a democratic society. National Academy Press, Washington, D.C., USA.

Wong, A. 2003. Reversing the high prevalence of obesity, diabetes, hypertension and depression among the Aboriginal people. Pages 76-80 in A. Wong, editor, First Nations Nutrition and Health Conference Proceedings. Arbokem, Vancouver, British Columbia, Canada. 